\title{
Pengembangan Laboratory Information System untuk Memperbaiki Waktu Tunggu Layanan
}

\section{Development of Laboratory Information System to Improve Services Turnaround Time}

\author{
Eky Indyanty $W^{1}$, Ahas Loekqijana $A^{2}$, Tri Putri $Y^{3}$ \\ ${ }^{1}$ Program Studi Magister Manajemen Rumah Sakit, Fakultas Kedokteran Universitas Brawijaya \\ ${ }^{2}$ Rumah Sakit Umum Daerah Ngudi Waluyo Wlingi Kabupaten Blitar \\ ${ }^{3}$ Instalasi Patologi Klinik Rumah Sakit Umum Daerah Kabupaten Jombang
}

\begin{abstract}
ABSTRAK
Penelitian ini merupakan studi observasional dengan desain cross-sectional yang bertujuan untuk mencari akar masalah dan alternatif solusi masalah pemanjangan turnaround time (TAT) layanan laboratorium di Instalasi Patologi Klinik RSUD Kabupaten Jombang. Pada penelitian ini didapatkan sejumlah subjek 103 orang yang melakukan pemeriksaan darah lengkap, kimia klinik, serta keduanya. Penentuan akar masalah dengan diagram fishbone. Identifikasi alternatif solusi masalah dilakukan melalui pohon alternatif solusi sedangkan pemilihan solusi dilakukan melalui teori tapisan Mc Namara dan pendekatan cost benefit analysis. Data kuantitatif dianalisis menggunakan uji Kolmogorov-Smirnov untuk menilai normalitas serta paired $t$-test untuk menentukan uji beda reratadengan taraf signifikansi $p \leq 0,05$. Dari hasil penelitian didapatkan pemanjangan waktu tunggu saat spesimen selesai dikerjakan oleh analyzer sampai hasil dilaporkan karena proses ini dilakukan secara manual. Alternatif solusi yang dipilih berdasarkan teori tapisan Mc Namara dan cost benefit analysis adalah penggunaan laboratory information system (LIS). Estimasi TAT dengan pemakaian LIS dapat memendek secara bermakna pada pasien rawat inap untuk pemeriksaan darah lengkap $(103,00 \pm 77,74$ menit; $p<0,0001)$, kimia klinik $(107,33 \pm 83,32$ menit; $p<0,0001)$, dan keduanya $(138,43 \pm 82,65$ menit; $p<0,0001)$. Pada pasien rawat jalan hanya pada pemeriksaan kimia klinik $(161,84 \pm 129,90$ menit; $p<0,0001)$ dan keduanya $(94,90 \pm 34,35$ menit; $p<0,0001)$. Dapat dismpulkan laboratory information system dapat mengurangi pemanjangan TAT secara bermakna.
\end{abstract}

Kata Kunci: Laboratory information system (LIS), pelayanan laboratorium, turnaround time (TAT)

\begin{abstract}
This is an observational study with cross-sectional design that aims to find the root cause and alternative solutions for elongation of laboratory services turnaround time (TAT) in the Clinical Pathology Department of Jombang District Hospital. In this study, the number of subjects was 103 people who perform a complete blood count, clinical chemistry, and both. Determination of the root of the problem was done using a fishbone diagram. Identification of alternative solutions to the problems is done through the use of the alternative solutions trees while the selection is done through a Mc Namara theoretical solution strainer and cost benefit analysis (CBA) approach. Quantitative data were analyzed using the Kolmogorov-Smirnov test to assess normality, and paired t-test to determine the mean difference. The results of this study showed that elongation of the TAT was due to protracted waiting time, from the time specimen was substantially completed by the analyzer until the results are reported. Due to manually system alternative solutions selected based on the theory of Mc Namara strainer and CBA is the use of laboratory information system (LIS). With the use of LIS, estimated TAT for hospitalized patients can be significantly shortened for a complete blood count $(103,00 \pm 77,74 \mathrm{~min}, p<0,0001)$, clinical chemistry $(107,33 \pm 83,32 \mathrm{~min}, p<0,0001)$, and both $(138,43 \pm 82,65 \mathrm{~min}, p<0,0001)$. The corresponding results for the outpatient based analysis on clinical chemistry is $161,84 \pm 129,90 \mathrm{~min}(p<0,0001)$ and for both examination $94,90 \pm 34,35 \mathrm{~min}(p<0,0001)$. It can be concluded that laboratory information system can significantly reduce the elongation of the TAT.
\end{abstract}

Keywords: Laboratory information system (LIS), laboratory services, turnaround time (TAT)

Jurnal Kedokteran Brawijaya, Vol. 28, No. 1, Februari 2014; Korespondensi: Eky Indyanty WL. Program Studi Magister Manajemen Rumah Sakit Fakultas Kedokteran Universitas Brawijaya; J. Veteran Malang (0341) 568989; Email: ekyindyanty@gmail.com 


\section{PENDAHULUAN}

Pelayanan laboratorium mempunyai peranan penting dalam pelayanan pasien di rumah sakit, hasil laboratorium diperkirakan memegang peranan sekitar 60$70 \%$ dalam hal keputusan rawat inap, pasien pulang, dan pengobatan (1). Pelayanan laboratorium yang efektif dan efisien ditandai oleh 3 hal yaitu presisi, akurat, dan ketepatan waktu yang dinilai dengan turnaround time (TAT) $(2,3)$. Turnaround time sering digunakan oleh klinisi sebagai patokan performa atau indikator kinerja yang utama pada pelayanan laboratorium $(2,4)$. Dilaporkan bahwa fase pra-analitik dan pasca-analitik merupakan fase yang berkontribusi sekitar $75 \%$ dari total TAT, dan keterlambatan dari fase non-analitik ini bertanggung jawab sekitar $96 \%$ dari total TAT(2).

Turnaround time didefinisikan oleh para profesional laboratorium klinik sebagai waktu yang diukur mulai dari spesimen diterima dilaboratorium sampai hasil dilaporkan. Para klinisi memberikan definisi yang berbeda yaitu waktu mulai permintaan tes laboratorium sampai dengan hasil dilaporkan $(3,4)$. Menurut Permenkes No.129/Menkes/SK/II/2008 tentang standar pelayanan minimal (SPM) rumah sakit, waktu tunggu hasil pelayanan laboratorium untuk pemeriksaan laboratorium adalah tenggang waktu mulai pasien diambil sampel sampai dengan menerima hasil yang sudah diekspertisi, dengan standar waktu $\leq 140$ menit untuk pemeriksaan kimia darah dan darah rutin.

Turnaround time di Instalasi Patologi Klinik RSUD Kabupaten Jombang belum memenuhi standar dengan pencapaian pada laporan tahun 2012 melebihi waktu yang ditentukan oleh SPM yaitu 166 menit, meningkat $18 \%$ dari standar (5). Pemanjangan waktu tunggu hasil layanan laboratorium ini merupakan salah satu masalah yang harus segera diselesaikan agar tidak menghambat pelayanan di rumah sakit. Kajian ini dilakukan untuk mencari akar masalah dari pemanjangan TAT sebagai dasar dalam mengembangkanalternatif solusi terbaik.

\section{METODE}

Penelitian ini merupakan penelitian observasional dengan desain cross sectional survey. Waktu tunggu layanan laboratorium dihitung pada pasien yang melakukan pemeriksaan laboratorium darah lengkap, kimia klinik atau keduanya di Instalasi Patologi Klinik RSUD Kabupaten Jombang pada pukul 08.00 sampai dengan 12.00 WIB dengan cara accidental sampling. Jumlah subjek untuk perhitungan TAT terkumpul sebesar 103 orang (51 pasien rawat jalan dan 52 pasien rawat inap) yang melakukan pemeriksaan darah lengkap, kimia klinik, serta keduanya. Besar subjek dihitung dari jumlah $50 \%$ kunjungan pasien rawat inap dan rawat jalan di laboratorium RSUD Kabupaten Jombang per hari.

Variabel yang diukur adalah waktu tunggu mulai spesimen diterima oleh laboratorium sampai dengan hasil pemeriksaan dilaporkan. Waktu ini dibagi menjadi 3 poin yaitu waktu saat spesimen diterima di laboratorium sampai dengan selesai diperiksa di analyzer, waktu saat spesimen selesai diperiksa di analyzer sampai dengan hasil dilaporkan, dan total waktu mulai dari spesimen diterima di laboratorium sampai dengan hasil dilaporkan. Analyzer otomatis yang digunakan untuk pemeriksaan darah lengkap adalah Sysmex KX-21 Automated Hematology Analyzer (Sysmex Co., Kobe Japan) sedangkan analyzer yang digunakan untuk pemeriksaan kimia klinik adalah Selectra ProSClinical Chemistry Analyzer (Vital Scientific, Netherland).
Penentuan akar masalah pemanjangan TAT menggunakan diagram fishbone berdasarkan pada man, machine, method, money, dan material dari pengamatan/observasi, wawancara, dan brainstorming. Identifikasi alternatif solusi permasalahan dilakukan melalui pohon alternatif solusi dan pemilihan solusi dilakukan melalui teori tapisan Mc Namara dan pendekatan cost benefit analysis (6).

Rerata TAT, standar deviasi, nilai maksimum dan minimum (dalam menit) pada masing-masing waktu tunggu dianalisis pada pasien rawat jalan dan rawat inap. Data kuantitatif waktu tunggu pada masing-masing kelompok pemeriksaan (darah lengkap, kimia klinik, dan keduanya) dianalisis dengan menggunakan SPSS versi 19. Uji Kolmogorov-Smirnov (K-S) menunjukkan data mempunyai distribusi normal sehingga untuk membandingkan TAT sebelum solusi masalah dan estimasi TAT setelah implementasi solusi masalah digunakan uji statistic paired $t$-test dengan taraf signifikansi $p \leq 0,05$.

\section{HASIL}

Hasil perhitungan waktu tunggu masing-masing tahap pemeriksaan dijelaskan pada Tabel 1-3. Tabel 1 menunjukkan rerata waktu tunggu mulai spesimen diterima laboratorium sampai dengan selesai dikerjakan oleh analyzer. Pada Tabel 1 terlihat bahwa waktu pemeriksaan kimia klinik pada pasien rawat jalan memiliki durasi waktu analitik paling panjang $(136,42 \pm 13,17$ menit) dibandingkan pemeriksaan lain.

Tabel 1. Deskripsi rerata waktu tunggu mulai spesimen diterima laboratorium sampai dengan selesai dikerjakan oleh analyzer

\begin{tabular}{lccccc}
\hline \multicolumn{1}{c}{ Parameter } & $\begin{array}{c}\text { Jumlah } \\
\text { (orang) }\end{array}$ & $\begin{array}{c}\text { Rerata } \\
\text { (menit) }\end{array}$ & $\begin{array}{c}\text { Standar } \\
\text { deviasi (menit) }\end{array}$ & $\begin{array}{c}\text { Minimum- } \\
\text { Maksimum(menit) }\end{array}$ \\
\hline Rawat & DL & 2 & 69,00 & 36,77 & $43-95$ \\
Jalan & KK & 38 & 136,42 & 13,17 & $114-180$ \\
& DL dan KK & 11 & 124,82 & 35,60 & $39-166$ \\
Rawat & DL & 17 & 57,59 & 28,16 & $4-104$ \\
Inap & KK & 21 & 117,33 & 27,22 & $66-167$ \\
& DL dan KK & 14 & 120,57 & 16,81 & $79-140$ \\
\hline
\end{tabular}

\section{Keterangan:}

DL: darah lengkap; KK: kimia klinik; DL dan KK: darah lengkap dan kimia klinik

Tabel 2 menunjukkan rerata waktu tunggu mulai dari spesimen selesai dikerjakan oleh analyzer sampai dengan hasil dilaporkan kepada dokter atau pasien. Pada Tabel 2 terlihat bahwa hasil laboratorium tidak langsung dilaporkan kepada dokter atau pasien, namun terdapat waktu tunggu yang berlarut-larut sekitar 112,24 $\pm 78,32$ menit sampai dengan $212,79 \pm 91,35$ menit.

Tabel 2. Deskripsi rerata waktu tunggu mulai dari spesimen selesai dikerjakan oleh analyzer sampai dengan hasil dilaporkan

\begin{tabular}{|c|c|c|c|c|c|}
\hline & Parameter & $\begin{array}{l}\text { Jumlah } \\
\text { (orang) }\end{array}$ & $\begin{array}{l}\text { Rerata } \\
\text { (menit) }\end{array}$ & $\begin{array}{c}\text { Standar } \\
\text { deviasi (menit) }\end{array}$ & $\begin{array}{c}\text { Minimum- } \\
\text { Maksimum (menit) }\end{array}$ \\
\hline Rawat & $\mathrm{DL}$ & 2 & 167,00 & 63,64 & $122-212$ \\
\hline \multirow[t]{2}{*}{ Jalan } & KK & 38 & 171,84 & 129,91 & $38-450$ \\
\hline & DL dan KK & 11 & 172,73 & 38,04 & $76-207$ \\
\hline Rawat & $\mathrm{DL}$ & 17 & 112,24 & 78,32 & $50-294$ \\
\hline \multirow[t]{2}{*}{ Inap } & KK & 21 & 117,33 & 83,31 & $7-253$ \\
\hline & DL dan KK & 14 & 212,79 & 91,35 & $62-357$ \\
\hline
\end{tabular}


Tabel 3 menunjukkan rerata total waktu tunggu mulai spesimen diterima di laboratorium sampai dengan hasil dilaporkan kepada dokter atau pasien. Pada Tabel 3 terlihat bahwa total waktu tunggu yang dikenal sebagai turnaround time pelayanan laboratorium sangat memanjang. Pemeriksaan kimia klinik pada pasien rawat jalan mencapai waktu tertinggi yaitu $308,26 \pm 133,59$ menit.

Tabel 3. Deskripsi rerata total waktu tunggu mulai spesimen diterima di laboratroium sampai dengan hasil dilaporkan

\begin{tabular}{lccccc}
\hline \multicolumn{2}{c}{ Parameter } & $\begin{array}{c}\text { Jumlah } \\
\text { (orang) }\end{array}$ & $\begin{array}{c}\text { Rerata } \\
\text { (menit) }\end{array}$ & $\begin{array}{c}\text { Standar } \\
\text { deviasi (menit) }\end{array}$ & $\begin{array}{c}\text { Minimum- } \\
\text { Maksimum (menit) }\end{array}$ \\
\hline Rawat & DL & 2 & 236,00 & 100,41 & $165-307$ \\
Jalan & KK & 38 & 308,26 & 133,59 & $159-595$ \\
& DL dan KK & 11 & 229,73 & 17,21 & $207-262$ \\
Rawat & DL & 17 & 170,59 & 76,68 & $65-323$ \\
Inap & KK & 21 & 234,67 & 83,16 & $123-382$ \\
& DL dan KK & 14 & 269,00 & 79,49 & $159-388$ \\
\hline
\end{tabular}

Keterangan:

DL: darah lengkap; KK: kimia klinik; DL dan KK: darah lengkap dan kimia klinik

Diagram fishbone digunakan untuk menentukan akar masalah pemanjangan TAT. Pada faktorman, jumlah sumber daya manusia (SDM) terutama analis kesehatan terpenuhi sesuai dengan analisis beban kerja serta standar pendidikan minimal yang telah ditetapkan. Jumlah dan ketelitian tenaga administrasi masih kurang. Pada method didapatkan sistem billing yang masih kurang sempurna (terdapat beberapa item yang belum berfungsi dengan benar) serta sistem input pelaporan hasil yang masih dikerjakan secara manual (hasil dari alat ditulis manual di buku dan formulir permintaan serta diketik secara manual ke komputer hasil).

Pada material, terdapat standar prosedur operasional (SPO) yang jelas tentang pelayanan pemeriksaan laboratorium. Sarana dan prasarana pencatatan pasien serta hasil laboratorium sudah berbasis komputer meskipun sistemnya belum sempurna. Pada machine, terdapat alat analyzer yang cukup canggih dengan jumlah yang memadai. Pada money, terdapat anggaran yang cukup untuk pengembangan program serta pendapatan laboratorium yang cukup besar. Pada environment didapatkan tempat kerja yang cukup luas dan kondusif serta budaya kerja karyawan yang sudah cukup baik. Pada diagram fishbone terlihat adanya gap nyata pada method sehingga ditentukan akar masalah pemanjangan TAT adalah sistem billing yang masih belum sempurna dan sistem pencatatan hasil yang dilakukan secara manual.

Metode untuk menemukan alternatif solusi pada penelitian ini adalah metode pohon alternatif. Dari pohon alternatif, alternatif solusi masalah sistem pencatatan yang dilakukan secara manual untuk mengurangi pemanjangan TAT antara lain penambahan tenaga administrasi dan pemakaian laboratory information system (LIS). Dari alternatif solusi tersebut ditentukan pemilihan alternatif terbaik yang dilakukan dalam rangka memilih alternatif yang paling menguntungkan bagi rumah sakit. Pemilihan alternatif solusi dilakukan melalui tapisan Mc Namara dan didapatkan alternatif solusi yang dipilih adalah pemakaian LIS. didapatkan total keuntungan dalam 10 tahun berjalan lebih besar dari total biaya yang dikeluarkan, dengan rasio benefit: cost sama dengan 3, selisih benefit dibandingkan cost yang positif dan internal rate return (IRR) sebesar $218 \%$. Hal ini menunjukkan bahwa dengan pemakaian LIS, manfaat yang didapatkan lebih besar daripada biaya yang dikeluarkan dengan laju pengembalian (rate to return) yang cukup besar.

Tabel 4 menunjukkan rerata estimasi total waktu tunggu mulai spesimen diterima di laboratorum sampai hasil dilaporkan jika digunakan LIS. Estimasi total waktu tunggu didapatkan dari jumlah waktu tunggu mulai spesimen diterima di laboratorium sampai dengan spesimen selesai dikerjakan oleh analyzer ditambahkan 10 menit. Penambahan 10 menit pada estimasi waktu ini didasarkan pada rerata waktu tunggu yang dibutuhkan mulai spesimen selesai dikerjakan analyzer dan diverifikasi oleh dokter Spesialis Patologi Klinik berdasarkan pengalaman rumah sakit dengan tipe sama yang sudah menerapkan LIS.

Tabel 4. Deskripsi rerata estimasi total waktu tunggu mulai spesimen diterima di laboratorium sampai hasil dilaporkan dengan pemakaian laboratory information system

\begin{tabular}{lccccc}
\hline \multicolumn{1}{c}{ Parameter } & $\begin{array}{c}\text { Jumlah } \\
\text { (orang) }\end{array}$ & $\begin{array}{c}\text { Rerata } \\
\text { (menit) }\end{array}$ & $\begin{array}{c}\text { Standar } \\
\text { deviasi (menit) }\end{array}$ & $\begin{array}{c}\text { Minimum- } \\
\text { Maksimum(menit) }\end{array}$ \\
\hline Rawat DL & 2 & 79,00 & 36,77 & $50-105$ \\
Jalan KK & 38 & 146,42 & 13,17 & $124-190$ \\
& DL dan KK & 11 & 134,82 & 35,60 & $49-176$ \\
Rawat DL & 17 & 67,59 & 28,17 & $14-114$ \\
Inap KK & 21 & 127,33 & 27,22 & $76-177$ \\
& DL dan KK & 14 & 130,57 & 16,8 & $89-150$ \\
\hline
\end{tabular}

Rerata total waktu tunggu mulai dari spesimen diterima di laboratorium sampai dengan hasil dilaporkan dengan menggunakan LIS telah memenuhi standar dan tidak terdapat pemanjangan waktu tunggu yang berlarut-larut dengan rerata antara 79,00 $\pm 36,77$ menit sampai dengan $146,42 \pm 13,17$ menit (Tabel 4).

Uji normalitas (uji K-S) pada data masing-masing waktu menunjukkan distribusi data tersebut adalah normal. Perbedaan reratatotal waktu tunggu dari mulai spesimen diterima di laboratorium sampai dengan hasil dilaporkan secara manual dan estimasi total waktu tunggu dengan pemakaian LIS digunakan uji statistik paired t-test (Tabel 5).

Tabel 5. Perbedaan rerata total waktu tunggu layanan laoratorium antara secara manual dan pemakaian LIS

\begin{tabular}{|c|c|c|c|c|c|}
\hline & \multirow[b]{2}{*}{ Parameter } & \multirow[b]{2}{*}{$\begin{array}{c}\text { Mean Differences } \\
\pm \text { SD (menit) }\end{array}$} & \multicolumn{3}{|c|}{ Hasil Uji } \\
\hline & & & $\mathbf{t}$ & $\mathbf{p}$ & $\begin{array}{l}\text { 95\% Confidence } \\
\text { Interval (menit) }\end{array}$ \\
\hline \multirow{3}{*}{$\begin{array}{l}\text { Rawat } \\
\text { Jalan }\end{array}$} & $\mathrm{DL}$ & & 3,489 & 0,178 & $-414,78-728,78$ \\
\hline & KK & & 7,680 & $<0,0001$ & 11 \\
\hline & DL dan KK & $94,90 \pm 34,35$ & 9,164 & $<0,0001$ & $71,83-$ \\
\hline \multirow{3}{*}{$\begin{array}{l}\text { Rawat } \\
\text { Inap }\end{array}$} & $\mathrm{DL}$ & $103,00 \pm 77,74$ & 5,463 & $<0,0001$ & $63,03-142,97$ \\
\hline & KK & $107,33 \pm 83,32$ & 5,904 & $<0,0001$ & $69,41-145,26$ \\
\hline & DL dan KK & $138,43 \pm 82,65$ & 6,267 & $<0,0001$ & $90,71-186,15$ \\
\hline
\end{tabular}

Keterangan:

DL: darah lengkap; KK: kimia klinik; DL dan KK: darah lengkap dan kimia klinik

Pemakaian LIS dapat mengurangi pemanjangan TAT secara 
bermakna pada pasien rawat inap untuk pemeriksaan laboratorium darah lengkap $(103,00 \pm 77,74$ menit; $95 \% \mathrm{Cl}$ $63,03-142,97 ; p<0,0001)$, kimia klinik $(107,33 \pm 83,32$ menit; $95 \% \mathrm{Cl} 69,41-145,26 \mathrm{p}<0,0001)$, dan keduanya $(138,43 \pm 82,65$ menit; $95 \% \mathrm{Cl} 90,71-186,15 ; p<0,0001)$. Pada pasien rawat jalan pemakaian LIS dapat mengurangi pemanjangan TAT secara signifikan pada pemeriksaan kimia klinik (161,84 $\pm 129,90$ menit; $95 \% \mathrm{Cl} 119,14-204,54$; $\mathrm{p}<0,0001)$ dan keduanya $(94,90 \pm 34,35$ menit; $95 \% \mathrm{Cl}$ 71,83-117,99; $p<0,0001$ ), namun pada pemeriksaan laboratorium darah lengkap di rawat jalan tidak terdapat perbedaan bermakna $(157,00 \pm 63,64$ menit; $95 \% \mathrm{Cl}$ $414,78-728,78 ; p=0,178)$.

\section{DISKUSI}

Rerata waktu tunggu mulai spesimen diterima di laboratorium sampai dengan spesimen selesai dikerjakan oleh analyzer telah memenuhi standar, namun terjadi pemanjangan rerata total waktu tunggu mulai dari spesimen diterima di laboratorium sampai dengan hasil dilaporkan. Hal ini dikarenakan terdapat pemanjangan waktu tunggu pada saat spesimen selesai dikerjakan di analyzer sampai hasil dilaporkan. Hasil temuan penelitian ini menunjukkan terdapat pemanjangan TAT layanan laboratorium di RSUD Kabupaten Jombang disebabkan oleh sistem pencatatan yang dilakukan secara manual.

Pada fase analitik, waktu tunggu yang dibutuhkan untuk melakukan pemeriksaan darah lengkap, kimia klinik dan keduanya dalam analyzer masih sesuai dengan standar yaitu $\leq 140$ menit yaitu dengan rerata $69,00 \pm 36,77$ menit sampai dengan $136,42 \pm 13,17$ menit. Terjadi pemanjangan waktu pada fase pasca-analitik yaitu kegiatan pencatatan hasil dari analyzer ke dalam buku pemeriksaan dan formulir permintaan pemeriksaan dengan rerata $167,00 \pm 63,64$ menit sampai dengan $212,79 \pm 91,35$ menit.

Dengan demikian total waktu tunggu dari spesimen diterima di laboratorium sampai dengan hasil dilaporkan semakin memanjang yaitu dengan rerata $170,59 \pm 76,68$ menit sampai dengan $308,26 \pm 133,59$ menit. Oleh karena itu pemanjangan waktu berlarut-larut yang disebabkan oleh sistem pencatatan hasil pada fase pasca-analitik seharusnya dapat dihilangkan. Berdasarkan analisis menggunakan teori tapisan Mc Namara didapatkan bahwa implementasi LIS merupakan solusi terbaik untuk mengurangi pemanjangan TAT tersebut.

Chung et al melaporkan hasil penelitian analisis TAT pada 3 fase pemeriksaan di laboratorium yang telah mengimplementasikan LIS didapatkan bahwa rerata TAT untuk pemeriksaan kimia klinik adalah $43,6 \pm 7,7$ menit. Sebanyak $98 \%$ dari spesimen diselesaikan dalam waktu 60 menit. Chung et al juga melaporkan waktu penyelesaian masing-masing fase mulai dari fase pra-analitik, analitik dan pasca-analitik berturut-turut $29,7 \pm 6,9$ menit,

\section{DAFTAR PUSTAKA}

1. Da Rin G. Pre-Analytical Workstations: A Tool for Reducing Laboratory Errors. Clinica Chimica Acta. 2009; 404(1): 68-74.

2. Goswami B, Singh B, Chawla R, Gupta VK, and Mallika V. Turn Around Time (TAT) as a Benchmark of Laboratory Performance. The Indian Journal of Clinical Biochemistry. 2010; 25(4): 376-379.

3. Goswami B, Singh B, Chawla R, and Mallika V. Evaluation of Error in a Clinical Laboratory: A One-
$13,9 \pm 4,1$ menit, dan 0,02 $\pm 0,13$ menit (4). Penelitian Chung et al ini menunjukkan bahwa terdapat efisiensi waktu tunggu jika diimplemetasikan LIS.

Penelitian yang dilakukan oleh Ricos et al melaporkan bahwa $11 \%$ dari spesimen yang diperiksa di laboratorium tidak selesai sesuai dengan batas waktu yang telah ditentukan (7). Ketepatan waktu sangat penting bagi klinisi yang mungkin dapat mengorbankan kualitas analisis untuk TAT yang cepat, namun para profesional laboratorium lebih memilih menjaga kualitas analisis sama baiknya dengan mengurangi TAT (3). Pengurangan TAT seharusnya dapat meningkatkan kualitas pelayanan. Implementasi teknologi informasi dalam hal ini LIS dapat memperbaiki keterlambatan dalam pelaporan di laboratorium dan menguramgi pemanjangan dari TAT tanpa mengurangi kualitas pelayanan itu sendiri(8).

Pada penelitian ini terdapat pengurangan waktu tunggu yang bermakna jika dilakukan implementasi LIS pada pasien yang melakukan pemeriksaan laboratorium darah lengkap, kimia klinik, dan keduanya pada pasien rawat inap dan rawat jalan. Estimasi rerata penghematan waktu tunggu yang didapatkan dari implemetasi LIS sekitar $94,90 \pm 34,35$ menit sampai dengan $161,84 \pm 129,90$ menit. Oleh karena itu implementasi LIS pada laboratorium dapat menjadi solusi untuk menyelesaikan masalah pemanjangan TAT, tidak hanya di RSUD Kabupaten Jombang namun juga dapat diimplementasikan pada laboratorium RS lain.

Keterbatasan penelitian ini, TAT pasien rawat jalan yang melakukan pemeriksaan darah lengkap tidak terdapat perbedaan bermakna antara waktu tunggu manual dan menggunakan implementasi LIS. Hal ini dapat disebabkan oleh jumlah subjek pasien rawat jalan yang melakukan pemeriksaan darah lengkap terlalu kecil. Selain itu, pengambilan data primer pada penelitian ini dilakukan pada hari Jumat dan Sabtu selama 3 minggu berturut-turut dalam 1 bulan, sehingga belum dapat menggambarkan keadaan pada pelayanan laboratorium dihari kerja yang lain (Senin-Kamis) yang mungkin dapat ditemukan hasil yang berbeda.

Rerata waktu tunggu pemeriksaan darah lengkap, kimia klinik, serta keduanya di RSUD Kabupaten Jombang adalah $170,59 \pm 76,68$ menit sampai dengan $308,26 \pm 133,59$ menit. Hal ini tidak memenuhi standar SPM yaitu 140 menit, sehingga pemanjangan waktu tunggu ini dapat berdampak besar terhadap pelayanan pasien terutama dalam hal keputusan terapi pasien. Pemanjangan waktu tunggu hasil layanan laboratorium di Instalasi Patologi Klinik RSUD Kabupaten Jombang disebabkan oleh sistem pencatatan hasil yang masih dilakukan secara manual. Implementasi laboratory information system (LIS) mempunyai potensi mengurangi secara signifikan pemanjangan waktu tunggu layanan laboratorium.

Year Experience. Clinical Chemistry and Laboratory Medicine. 2010; 48(1): 63-66.

4. Chung H-J, Lee W, Chun S, Park H-I, and Min W-K. Analysis of Turnaround Time by Subdividing Three Phases for Outpatient Chemistry Specimens. Annals of Clinical \& Laboratory Science. 2009; 39(2): 144-149.

5. RSUD Kabupaten Jombang. Laporan Tahunan Rumah Sakit Umum Daerah Kabupaten Jombang Tahun 2012. Jombang: RSUD Kabupaten Jombang; 2012.

6. Sianipar JPG dan Entang HM. Teknik-Teknik Analisis 
Manajemen. Di dalam: Sianipar JPG, Entang HM (Eds). Macam-macam Cara Analisis Manajemen. Jakarta: Lembaga Administrasi Negara Republik Indonesia; 2001; hal. 22-49.

7. Ricos C, Garcia-Victoria M, and de la Fuente B. Quality Indicators and Specifications for the Extra-Analytical Phases in Clinical Laboratory Management. Clinical
Chemistry and Laboratory Medicine. 2004; 42(6): 576 577.

8. Piva E, Sciacovelli L, Zaninotto M, Laposata M, and Plebani M. Evaluation of Effectiveness of Computerized Notifocation System for Reporting Critical Values. American Journal of Clinical Pathology. 2009; 131(3): 432-441. 